\title{
Diagnóstico de infecciones por dermatofitos en uñas con detección rápida específica de Trichophyton rubrum
}

\author{
Diagnosis of dermatophyte nail infections with a quick specific detection \\ of Trichophyton rubrum
}

\author{
Rebeca Prieto Riaño (1), Julia María Janeiro Arocas (2), Laura Fiaño Avilés (3), \\ Luisa Ibáñez Martínez (4), Alfonso Alba Menéndez (5), Cristina González Martín (6)
}

(1) Licenciada en Podología. Experto Universitario en Patología y Ortopedia del Miembro Inferior. Clínica Podológica O Camiño.

(2) Licenciada en Podología. Profesora Titular de la E.U. Enfermería y Podología de Ferrol. Universidad de A Coruña.

(3) Traumatóloga. Servicio de Cirugía Ortopédica y Traumatología, Hospital Lucus Augusti, Lugo, España.

(4) Traumatóloga. Servicio de Cirugía Ortopédica y Traumatología, Hospital Lucus Augusti, Lugo, España.

(5) Biólogo Molecular. Instituto de Estudios Celulares y Moleculares, I.C.M., Lugo, España.

(6) Licenciada en Antropología. Diplomada en Podología.

Profesora Colaboradora de la E.U. Enfermería y Podología de Ferrol. Universidad de A Coruña.

Correspondencia:

Rebeca Prieto Riaño

c/ Bouza no $4,4^{\circ}$ dcha.

27002 Lugo (España)

Fecha de recepción: 20 de noviembre de 2011

Fecha de aceptación: 27 de enero de 2011

Los autores declaran no tener ningún tipo de interés económico o comercial.

\section{RESUMEN}

El objetivo de este estudio es valorar la utilidad de la Polymerase Chain Reaction (PCR) como técnica alternativa al método clásico de diagnóstico de dermatofitos.

Para ello se ha utilizado un método de extracción rápido, en dos pasos, y una PCR multiplex para la detección de dermatofitos en general, y en especial de Trichophyton rubrum a partir de ADN extraído de controles y de uñas enfermas.

Como controles de ADN se emplearon: ADN humano y ADN de una serie de hongos dermatofíticos y no-dermatofíticos.

Se llevó a cabo un estudio descriptivo prospectivo de casos y controles en nuestra población de Lugo de un total de 28 muestras de uñas que fueron evaluadas de forma separada por dos PCR y en formato multiplex.

La comparación entre el método tradicional de diagnóstico en uñas (microscopía y cultivo) con el de PCR utilizando ADN extraído directamente de las uñas, muestra una excelente concordancia entre la microscopía y la PCR. Además, con el estudio mediante PCR el número de muestras identificadas con dermatofitos aumentó de un $20 \%$ a más de un $40 \%$ principalmente debido a la identificación de T.rubrum por PCR en muestras positivas por microscopía pero negativas en cultivo.

En conclusión, este test de diagnóstico rápido supone un notable incremento de la sensibilidad en la caracterización de las onicomicosis.

Palabras clave: dermatofitos, PCR, onicomicosis, Trichophyton rubrum. 


\section{ABSTRACT}

The aim of this study is to assess the usefulness of the Polymerase Chain Reaction (PCR) as an alternative technique to the classic method of diagnosis of dermatophytes.

To that end, a fast extraction method has been used, in two steps, and also a multiplex PCR in order to detect dermatophytes and, more in particular, Trichophyton rubrum from DNA extracted out of sick nails and previous tests.

As DNA controls we have used human DNA and DNA from a series of dermatophytes and nondermatophytic fungi.

A prospective descriptive study was carried out of cases and controls from our population in Lugo, where a total of 28 nail samples were analyzed separately, both by two PCR and a multiplex format.

The comparison between the traditional method of diagnosis in nails (microscopy and culture) and the PCR using DNA directly extracted from the nails shows an excellent concordance between the microscopy and the PCR.

In addition, with the study by PCR the number of samples identified with dermatophytes increased from a 20 percent to more than a 40 percent mainly due to the identification of T.rubrum by PCR in positive samples by microscopy but negative in culture.

In conclusion, this rapid diagnostic test represents a significant increase in sensitivity in the characterization of the onychomycosis.

Keywords: dermatofitos, PCR, onychomycosis, Trichophyton rubrum.

Sumario: 1. Introducción. 2. Material y método. 3. Resultados. 4. Discusión. 5. Concluisiones. Bibliografía.

Referencia normalizada: Prieto Riaño R, Janeiro Arocas JM, Fiaño Avilés L, Ibáñez Martínez L, Alba Menéndez A, González Martí C. Diagnóstico de infecciones por dermatofitos en uñas con detección rápida específica de Trichophyton rubrum. Rev. Int. Cienc. Podol. 2011; 5(2): 9-16. 


\section{INTRODUCCIÓN}

Los dermatofitos patógenos humanos son hongos queratinofílicos que infectan la piel, las uñas y el pelo. Existen tres géneros de estos organismos (Trichophyton, Microsporum $y$ Epidermophyton) con dianas de infección diferenciales. Las infecciones en uñas son causadas principalmente T. rubrum seguido de $T$. mentagrophytes mientras que en pelo y piel pueden ser causadas por otros dermatofitos incluyendo Microsporum sp. ${ }^{1,2,3,19,25,27}$

La prevalencia de onicomicosis en países europeos varía de un 3 a un $25 \%{ }^{9},{ }^{10}$. En un estudio en Summerbell et $\mathrm{al}^{26}$. donde se examinaron más de 2000 uñas afectadas, se aislaron los siguientes agentes: T. rubrum $(>70 \%)$, T. mentagrophytes (20\%), Candida albicans $(5,5 \%)$ y Scopulariopsis brevicaulis y otros no-dermatofitos $(1.6 \%)$.

Mientras que la identificación de dermatofitos antropofílicos puede ser considerada como representativa de un patógeno verdadero ${ }^{20,23}$, Candida y otros hongos no dermatofíticos pueden ser considerados contaminantes, agentes colonizadores o una infección secundaria debida a factores sistémicos locales?.

El diagnóstico actual está basado en la detección de elementos fúngicos por microscopia directa de especimenes clínicos seguida de cultivo in vitro e identificación morfológica del hongo $^{21}$. El examen por microscopia de piel y uñas suele ser suficiente para el diagnóstico de una infección fúngica ${ }^{22}$ pero no nos da identificación de género o especie de ahí que no se pueda diferenciar de manera segura entre los dermatofitos y otros hongos ${ }^{5,6}$. La posterior identificación de especies se realiza mediante un cultivo e identificación morfológica de las colonias de hongos ${ }^{24}$. El cultivo, sin embargo, es negativo en un $40 \%$ de los casos positivos por microscopia y además consume demasiado tiempo debido al lento crecimiento y esporulación y necesidad de más exámenes fisiológicos. El tiempo necesario para una identificación de especies puede variar desde 10-15 días hasta 3-4 semanas $^{28}$.

Un método rápido y simple de diagnóstico constituiría, sin dudas, una mejora muy importante. La introducción de una metodología basada en PCR podría aumentar especificidad, simplicidad, velocidad y potencialmente reducir costes ${ }^{4}$. Para estudios de identificación de especie y tipado se ha usado PCR, y las principales dianas han sido los genes o fragmentos de $\mathrm{ADN}$ de la región ribosomal, de la ADN topoisomerasa II y el gen de la quitin sinteta$\mathrm{sa}^{11,12}$.

El método alternativo de detección de dermatofitos utilizado se basa en una PCR multiplex especialmente desarrollada para la detección de onicomicosis. Mediante una extracción de ADN en dos pasos seguida de una PCR multiplex y una electroforesis, el método permite un diagnóstico de infección causada por cualquier dermatofito y en el caso de T. rubrum incluso la identificación de especie y género ${ }^{8,13}$. La extracción de ADN de solo 15 minutos y directamente de la muestra del paciente permite la aplicación de este método como método de diagnóstico de rutina ${ }^{29}$.

\section{MATERIAL Y MÉTODO}

- Cepas y aislados clínicos: Se han utilizado como controles los originales de la Collection of Pathogenic Fungi (United Kingdom). Los aislados clínicos fueron obtenidos en el laboratorio. Todos fueron identificados por observación macro y micromorfológica.

- Muestras de uñas: Veintiocho muestras de uñas recibidas para examen de rutina en el laboratorio fueron incluidas en el estudio. El único criterio de inclusión fue la presencia de suficiente cantidad de material para investigación por microscopia directa, cultivo y análisis por PCR.

- Obtención de ADN de los cultivos de dermatofitos: Las cepas y los aislados clínicos fueron cultivados en $2 \mathrm{~mL}$ de medio líquido Sabouraud con ciclohexamida y cloramfenicol e incubados con agitación hasta 8 días a $27^{\circ} \mathrm{C}$. Después del cultivo, el pellet se resuspendió en $500 \mu \mathrm{L}$ de tampón de lisis (400mM Tris- $\mathrm{HCl}[\mathrm{pH}=8]$, $60 \mathrm{mM}$ EDTA [pH=8], 150mM NaCl, 1\% de SDS) y se dejó a temperatura ambiente por $10 \mathrm{~min}$. A continuación se le añadió $150 \mu \mathrm{L}$ de acetato potásico $(\mathrm{pH}=4,8)$ se 
vortexeó y se centrifugó (1 min a 12000 $\mathrm{x} g$ ). El sobrenadante fue trasferido a un nuevo tubo y le fue añadido un volumen igual de isopropanol. El pellet (ADN) fue lavado con alcohol al 70\%, una vez seco, se resuspendió en $50 \mu \mathrm{L}$ de tampón TE (10mM Tris, 1mM EDTA). Fueron usados $2 \mu \mathrm{L}$ para la mezcla de PCR de 20 a $50 \mu \mathrm{L}$ (Reactivos obtenidos de Merck).

- Obtención de ADN de las uñas: En este caso el ADN se obtuvo incubando las muestras de uñas en $100 \mu \mathrm{L}$ de tampón de extracción $(60 \mathrm{mM} \mathrm{NaHCO} 3,250 \mathrm{mM} \mathrm{KCl}$ y $50 \mathrm{mM}$ Tris $\mathrm{pH}=9,5)$ por $10 \mathrm{~min}$ a $95^{\circ} \mathrm{C}$ y posterior adición de $100 \mu \mathrm{L}$ de tampón anti-inhibición (suero bovino al 2\%). Después de vortexear la solución queda lista para $\mathrm{PCR}^{18}$.

- PCR pan-dermatofitos: La composición de la PCR fué las siguiente:

- Set de primers para la quitin sintasa 1: D1 (5' GAA GAA GAT TGT CGT TTG CAT CGT CTC 3') y D2 (5' CTC GAG GTC AAA AGC ACG CCA GA 3').

- La mezcla de PCR consistió en $10 \mu \mathrm{L}$ de PCR Ready Mix, $0,2 \mu \mathrm{L}$ de cada primer a $100 \mu \mathrm{M}$ y $4 \mu \mathrm{L}$ de $\mathrm{ADN}$ para un volumen final de $20 \mu \mathrm{L}$. La PCR fue llevada a cabo en un termociclador Applied Biosystems

- Las condiciones de PCR empleadas fueron: Desnaturalización inicial: 10' a $95^{\circ} \mathrm{C} 45$ ciclos de desnaturalización: $30^{\prime \prime}$ a $94^{\circ} \mathrm{C}$; hibridación: $30^{\prime \prime}$ a $60^{\circ} \mathrm{C}$ y extensión: $30^{\prime \prime}$ a $72^{\circ} \mathrm{C}$. El tamaño del amplificado fue de aproximadamente 366 bp en un gel de agarosa al 1\%.

- PCR específica para T. rubrum: Basándose en el alineamiento de secuencias del NCBI, fueron diseñados un primer universal (U - 5' TCT TTG AAC GCA CAT TGC GCC 3') y uno T. rubrum específico (TrR, 5' CGG TCC TGA GGG CGC TGA A 3'). Cada reacción consistió en $10 \mu \mathrm{L}$ de PCR Ready Mix, $0,2 \mu \mathrm{L}$ de cada primer a $100 \mu \mathrm{M}$ y $4 \mu \mathrm{L}$ de $\mathrm{ADN}$ para un volumen final de $20 \mu \mathrm{L}$ y llevada a cabo en un termociclador Applied Biosystems.

- Las condiciones de PCR empleadas fueron: Desnaturalización inicial: $5^{\prime}$ a $94^{\circ} \mathrm{C}$
- 45 ciclos de desnaturalización: 30" a $94^{\circ} \mathrm{C}$; hibridación: $30^{\prime \prime}$ a $60^{\circ} \mathrm{C}$ y extensión: $30^{\prime \prime}$ a $72^{\circ} \mathrm{C}$.

- PCR multiplex: Fue realizada con los dos juegos de primers antes descritos en las siguientes condiciones ${ }^{16}$ : Desnaturalización inicial: $5^{\prime}$ a $94^{\circ} \mathrm{C}, 45$ ciclos de desnaturalización: $30^{\prime \prime}$ a $94^{\circ} \mathrm{C}$ : hibridación: $30^{\prime \prime}$ a $60^{\circ} \mathrm{C}$ y extensión: $30^{\prime \prime}$ a $72^{\circ} \mathrm{C}$. La especificidad de la PCR multiplex fue comprobada con ADN de todas las cepas y con ADN humano. Para estandarizar el procedimiento se usaron diferentes concentraciones de ADN y condiciones de PCR. Posteriormente fue llevada a cabo con las muestras de uñas recibidas para análisis de rutina ${ }^{15}$.

\section{RESULTADOS}

Evaluación de las PCRs pan-dermatofito y de T. rubrum usando ADN extraído de cultivos fúngicos:

El ADN extraído de las cepas de dermatofitos de referencia, los aislados dermatofiticos clínicos y los aislados fúngicos no-dermatofíticos (Tabla1), fué empleado para probar los primers de la PCR pan-dermatofito y los de $T$. rubrum tanto en PCRs independientes como en formato multiplex. Un amplificado de $203 \mathrm{bp}$ correspondiente a $T$. rubrum fue observado en todas las muestras de ADN de T. rubrum tanto en PCR separada como en la multiplex, y un amplificado de 366 bp fue obtenido en todas las muestras de ADN de dermatofitos tanto en PCR separada como en la multiplex. No se detectaron amplificados en ninguno de los casos analizados para las muestras de hongos no dermatofíticos o para las muestras de ADN humano. (100\% de sensibilidad y especificidad para los tres sistemas de PCR $)^{14}$.

Evaluación clínica de las PCRs pan-dermatofito y de T. rubrum usando ADN extraído directamente de las uñas:

Por diagnóstico convencional de las 28 muestras de uñas, 4 resultaron positivas para $T$. rubrum y 1 para $T$. rubrum y $T$. mentagrophytes, 1 para Trichophyton tonsurans, 3 para Alternaria sp., 1 para Acremonium sp., 1 para Aspergillus 
sp., 1 para Candida sp., 2 para $S$. brevicaulis y una para una levadura no identificada. Catorce muestras dieron negativo al microscopio y en cultivo y 6 fueron positivas al microscopio para hifas y conidios pero negativas para cultivo, estas muestras fueron consideradas positivas para hongos (pero no se pudo establecer identificación de género o especie). Las muestras positivas en cultivo para hongos no dermatofíticos fueron consideradas dermatofito-negativas por metodología convencional en comparación con los resultados de PCR. El ADN de estas 28 muestras fue extraído usando el método de extracción en 2 pasos. Fueron realizados los tres juegos de PCR con cada una de las 28 muestras. Todos los resultados de la PCR multiplex coincidieron con los de las PCR por separado, indicando esto que no hay perdida de sensibilidad en el formato multiplex.

Concluyendo, el $50,0 \%$ de las muestras fueron positivas para dermatofitos por PCR y solamente el $21,4 \%$ lo fueron por diagnóstico convencional (incluyendo las positivas por microscopia pero negativas en cultivo). De entre los especimenes que fueron positivos por microscopia y cultivo el $85,0 \%$ fueron confirmados por PCR como positivos para T. rubrum, el $12 \%$ fué negativo y 1 reportado como positivo para $T$. rubrum y T. mentagrophytes por diagnóstico convencional, fue pan-dermatofito positivo pero negativo para T. rubrum. Dos especimenes negativos por microscopia pero

Tabla 1.- Dermatofitos usados como referencia ${ }^{17}$

Epidermophyton floccosum
Microsporum audouinii
Microsporum canis
Microsporum gypseum
Microsporum nanum
Trichophyton mentagrophytes
Trichophyton rubrum
Trichophyton soudanese
Trichophyton terrestre
Trichophyton verrucosum
Trichophyton violaceum

Otros

Aspergillus sp. Cándida $s p$. positivos en cultivo resultaron negativos por PCR .

Todos los productos de PCR específicos para T. rubrum que se obtuvieron de muestras que no fueron diagnosticadas como T. rubrumpositivas por el método tradicional, fueron secuenciadas y comparadas con la secuencia referencia NCPF113 obteniéndose concordancia en todos los casos. El amplificado obtenido en la PCR pan-dermatofitos como T. rubrum y $T$. mentagrophytes positivos, también fue secuenciado y esta secuencia se comparó con la de referencia para T. mentagrophytes (NCPF224) confirmando el resultado.

Resumiendo, el número de muestras positivas fue aumentado en un $28,6 \%$ (21,4\% versus $50,0 \%$ de 28 especimenes fueron positivos por los métodos convencional y por PCR respectivamente). Además, debido a la presencia de un considerable número de muestras positivas por microscopia y negativas en cultivo, el porcentaje de identificación de especies fue casi duplicado gracias al uso de la PCR .

\section{DISCUSIÓN}

La detección en el día de infección por dermatofitos en uñas es evidentemente una gran mejora en el diagnóstico de la onicomicosis, permitiendo establecer el tratamiento rápidamente y solo a aquellos que tengan una infección por dermatofitos. A pesar que la distribución de especies varía entre las diferentes partes de mundo, T. rubrum está reportado como el principal agente causal, estando presente en un $63-89 \%$ de los casos. Al mismo tiempo, los dermatofitos pertenecientes al género menos susceptible a Terbinafine, Microsporum son unánimemente reportados como agente causal muy poco frecuente en onicomicosis y la detección de su $\mathrm{ADN}$ en una muestra, representará, por consecuencia, la presencia de una dermatofito susceptible a Terbinafibe, que en la mayoría de los casos y sin identificación de especies, brindará suficiente información al clínico.

La evaluación clínica para la detección de dermatofitos en general y de $T$. rubrum en particular en las muestras de uñas mediante la técnica de PCR muestra un aumento de la 
sensibilidad comparado con el diagnóstico convencional. En esta comparación, las muestras positivas por microscopia y negativas por cultivo, fueron consideradas como dermatofito-positivas por métodos tradicionales aunque no se puede descartar que esta infección pueda deberse a no-dermatofitos en algún caso.

Es común obtener cultivos negativos de paciente con dermatofitosis debido a dificultades en el muestreo (material insuficiente o uso de recortes de uñas en lugar de material subungual) o asociados a un tratamiento médico previo etc., en caso de microscopia positiva y posterior cultivo negativo siempre se debe investigar un poco más.

La interpretación de la presencia de hongos no-dermatofiticos en muestras de uñas está sujeto a controversia. Dicha presencia puede deberse a contaminación, colonización temporal o infección por un traumatismo u otra enfermedad, o incluso contaminación en el laboratorio. Por lo tanto se requeriría la repetición de la detección para poder considerarlo patológico e incluso en estos casos podría representar una infección secundaria a una condición patológica subyacente de la uña. El hecho de que en este estudio algún caso resultara positivo para estos hongos no-dermatofiticos y a su vez positivas para T. rubrum por PCR, podría indicar un rápido crecimiento del hongo colonizante o una verdadera doble infección. El uso del sistema en 2 pasos propuesto para extraer ADN directamente de las uñas y el sistema de PCR multiplex para la detección de cualquier dermatofito y/o T. rubrum, con un aumento de la sensibilidad comparado con el método tradicional, permite, por primera vez, la integración de un método basado en biología molecular al examen rutinario de onicomicosis incluso en laboratorios de diagnóstico que reciben gran cantidad de muestras.

\section{CONCLUSION}

La caracterización por PCR utiliza métodos de biología molecular que nos permite una identificación positiva más fidedigna en términos de sensibilidad, además de un aumento notable de la sensibilidad respecto a los métodos clásicos para la caracterización de dermatofitos. Por otro lado, la utilización masiva de esta tecnología no supone un aumento de costes respecto a los métodos clásicos por lo que en función de nuestros resultados sugerimos la utilización universal de las técnicas de biología molecular para la caracterización de dermatofitos.

En términos generales la sensibilidad diagnóstica de la PCR duplica la del diagnostico convencional, permite el análisis y detección de coinfecciones por diferentes patógenos y el coste por determinación no supera el del diagnostico convencional aun suponiendo una clara ventaja en términos de velocidad diagnostica.

El inconveniente que presenta este tipo de técnicas es la facilidad de contaminación cruzada al amplificarse cantidades ínfimas de ADN. Otro de los posibles inconvenientes es la posibilidad de sobrediagnosticar patologías en la que el hongo se encuentra en un nivel subclínico.

La detección en el mismo día de una infección por dermatofitos en uñas es evidentemente una gran mejora en el diagnóstico de la onicomicosis, además permite establecer el tratamiento con más rapidez y sólo a aquellos pacientes que tengan una infección por dermatofitos.

La evaluación clínica para la detección de dermatofitos en general y de T. rubrum en particular en las muestras de uñas mediante la técnica de PCR muestra un aumento de la sensibilidad cuando se compara con el diagnóstico convencional.

El hecho de que en este estudio algún caso resultara positivo para estos hongos no-dermatofiticos y a su vez positivas para T. rubrum por PCR, podría indicar un rápido crecimiento del hongo colonizante o una verdadera doble infección. El uso del sistema en 2 pasos propuesto para extraer ADN directamente de las uñas y el sistema de PCR multiplex para la detección de cualquier dermatofito y/o T. rubrum, con un aumento de la sensibilidad comparado con el método tradicional, permite, por primera vez, la integración de un método basado en biología molecular al examen rutinario de onicomicosis incluso en laboratorios de diagnóstico que reciben gran cantidad de muestras. Este estudio da esperanzas a que un futuro un diagnóstico rápido, específico y de bajo coste esté ampliamente disponible. 


\section{REFERENCIAS}

1. Rinaldi, M.G. 2000. Dermatophytosis: Epidemiological and microbiological update. J Am Acad Dermatol 43 (Supp15), S120-S124. http://dx.doi.org/10.1067/mjd.2000.110378

2. Elewski, B. E. 1998. Onychomycosis: pathogenesis, diagnosis, and management. Clin. Microbiol. Rev. 11:415-429.

3. Ellis, D. H., A. B. Watson, J. E. Marley, and T. G. Williams. 1997. Nondermatophytes in onychomycosis of the toenails. Br. J. Dermatol. 136:490-493.

4. Faggi, E., G. Pini, and E. Campisi. 2002. PCR fingerprinting for identification of common species of dermatophytes. J. Clin. Microbiol. 40:4804-4805.

5. Gentles, J. C. 1971. Laboratory investigations of dermatophyte infections of nails. Sabouraudia 9:149152.

6. Hainer, B. L. 2003. Dermatophyte infections. Am. Fam. Physician 67:101-108.

7. Harmsen, D., A. Schwinn, E. B. Brocker, and M. Frosch. 1999. Molecular differentiation of dermatophyte fungi. Mycoses 42:67-70.

8. Hay, R. J. 2001. The future of onychomycosis therapy may involve a combination of approaches. Br. J. Dermatol. 145(Suppl. 60):3-8.

9. Heikkila, H., and S. Stubb. 1995. The prevalence of onychomycosis in Finland. Br. J. Dermatol. 133:699-703. http://dx.doi.org/10.1111/j.1365-2133.1995.tb02741.x

10. Ilkit, M. 2005. Onychomycosis in Adana, Turkey: a 5-year study. Int. J. Dermatol. 44:851-854. http:// dx.doi.org/10.1111/j.1365-4632.2005.02265.x

11. Kanbe, T., Y. Suzuki, A. Kamiya, T. Mochizuki, M. Fujihiro, and A. Kikuchi. 2003. PCR-based identification of common dermatophyte species using primer sets specific for the DNA topoisomerase II genes. J. Dermatol. Sci. 32:151-161.

12. Kanbe, T., Y. Suzuki, A. Kamiya, T. Mochizuki, M. Kawasaki, M. Fujihiro, and A. Kikuchi. 2003. Species-identification of dermatophytes Trichophyton, Microsporum and Epidermophyton by PCR and PCR-RFLP targeting of the DNA topoisomerase II genes. J. Dermatol. Sci. 33:41-54.

13. Kano, R., A. Hirai, M. Muramatsu, T. Watari, and A. Hasegawa. 2003. Direct detection of dermatophytes in skin samples based on sequences of the chitin synthase 1 (CHS1) gene. J. Vet. Med. Sci. 65:267-270.

14. Kano, R., Y. Nakamura, S. Watanabe, H. Takahashi, H. Tsujimoto, and A. Hasegawa. 1998. Differentiation of Microsporum species by random amplification of polymorphic DNA (RAPD) and Southern hybridization analyses. Mycoses 41:229-233. http://dx.doi.org/10.1111/j.1439-0507.1998.tb00329.x

15. Kardjeva, V., R. Summerbell, T. Kantardjiev, D. Devliotou- anagiotidou, E. Sotiriou, and Y. Graser. 2006. Forty-eight-hour diagnosis of onychomycosis with subtyping of Trichophyton rubrum strains. J. Clin. Microbiol. 44:1419-427. http://dx.doi.org/10.1128/JCM.44.4.1419-1427.2006

16. Liu, D., S. Coloe, R. Baird, and J. Pedersen. 2000. Application of PCR to the identification of dermatophyte fungi. J. Med. Microbiol. 49:493-497.

17. Liu, D., L. Pearce, G. Lilley, S. Coloe, R. Baird, and J. Pedersen. 2002. PCR identification of dermatophyte fungi Trichophyton rubrum, T. soudanense and T. gourvilii. J. Med. Microbiol. 51:117-122.

18. Mahoney, J. M., J. Bennet, and B. Olsen. 2003. The diagnosis of onychomycosis. Dermatol. Clin. 21:463-467.

19. Monod, M., S. Jaccoud, C. Zaugg, B. Lechenne, F. Baudraz, and R. Panizzon. 2002. Survey of dermatophyte infections in the Lausanne area, Switzerland. Dermatology 205:201-203. http://dx.doi. org/10.1159/000063913

20. Mugge, C., U. F. Haustein, and P. Nenoff. 2006. Causative agents of onychomycosis a retrospective study. J. Dtsch. Dermatol. Ges. 4:218-228. http://dx.doi.org/10.1111/j.1610-0387.2006.05877.x

21. Petrini, B., and M. L. von Rosen. 2002. Optimal dermatophyte diagnosis requires both microscopy and culture. Lakartidningen 99:4084.

22. Rippon, J. W. 1988. Medical mycology: the pathogenic fungi and the pathogenic actinomycetes. W. B. Saunders Co., Philadelphia, PA.

23. Romano, C., C. Gianni, and E. M. Difonzo. 2005. Retrospective study of onychomycosis in Italy: 1985-2000. Mycoses 48:42-44.

24. Shin, J. H., J. H. Sung, S. J. Park, J. A. Kim, J. H. Lee, D. Y. Lee, E. S. Lee, and J. M. Yang. 2003. Species identification and strain differentiation of dermatophyte fungi using polymerase chain reaction amplification and restriction enzyme analysis. J. Am. Acad. Dermatol. 48:857-865. 
25. Singh, D., D. C. Patel, K. Rogers, N. Wood, D. Riley, and A. J. Morris. 2003. Epidemiology of dermatophyte infection in Auckland, New Zealand. Australas. J. Dermatol. 44:263-266.

26. Summerbell, R. C., J. Kane, and S. Krajden. 1989. Onychomycosis, tinea pedis and tinea manuum caused by non-dermatophytic filamentous fungi. Mycoses 32:609-619.

27. Svejgaard, E. L., and J. Nilsson. 2004. Onychomycosis in Denmark: prevalence of fungal nail infection in general practice. Mycoses 47:131-135.

28. Weinberg, J. M., E. K. Koestenblatt, W. D. Tutrone, H. R. Tishler, and L. Najarian. 2003. Comparison of diagnostic methods in the evaluation of onychomycosis. J. Am. Acad. Dermatol. 49:193-197.

29. Weitzman, I., and R. C. Summerbell. 1995. The dermatophytes. Clin. Microbiol.Rev. 8:240-259. 